\title{
A NEW FISH SCALE-DERIVED SCAFFOLD FOR CORNEAL REGENERATION
}

\author{
Chien Chen Lin ${ }^{1,6}$, Robert Ritch ${ }^{2,3}$, Shang Ming Lin ${ }^{4}$, Mei-Hui Ni ${ }^{6}$, Yu-Chung Chang ${ }^{1,6}$, Yi Lung Lu ${ }^{6}$, Horng Ji Lai ${ }^{5}$, \\ and Feng-Huei $\operatorname{Lin}^{1 *}$
}

'Institute of Biomedical Engineering, National Taiwan University, Taipei 100, Taiwan, ROC

${ }^{2}$ Einhorn Clinical Research Center, New York Eye and Ear Infirmary, New York, NY, USA

${ }^{3}$ Department of Ophthalmology, The New York Medical College, Valhalla, NY, USA

${ }^{4}$ Department of Textile Engineering, Oriental Institute of Technology, Taipei County 220, Taiwan, ROC

${ }^{5}$ Department of Research, Aeon Astron Europe B.V., Leiden, The Netherlands

${ }^{6}$ Department of Research, Aeon Astron Corp., Taipei 10595, Taiwan, ROC.

\begin{abstract}
The purpose of this study is to develop a novel scaffold, derived from fish scales, as an alternative functional material with sufficient mechanical strength for corneal regenerative applications. Fish scales, which are usually considered as marine wastes, were acellularized, decalcified and fabricated into collagen scaffolds. The microstructure of the acellularized scaffold was imaged by scanning electron microscopy (SEM). The acellularization and decalcification treatments did not affect the naturally 3dimentional, highly centrally-oriented micropatterned structure of the material. To assess the cytocompatibility of the scaffold with corneal cells, rabbit corneal cells were cultured on the scaffold and examined under SEM and confocal microscopy at different time periods. Rapid cell proliferation and migration on the scaffold were observed under SEM and confocal microscopy. The highly centrallyoriented micropatterned structure of the scaffold was beneficial for efficient nutrient and oxygen supply to the cells cultured in the three-dimensional matrices, and therefore it is useful for high-density cell seeding and spreading. Collectively, we demonstrate the superior cellular conductivity of the newly developed material. We provide evidences for the feasibility of the scaffold as a template for corneal cells growth and migration, and thus the fish scale-derived scaffold can be developed as a promising material for tissue-engineering of cornea.
\end{abstract}

Keywords: Artificial cornea, biocornea, corneal regeneration, tissue engineering, scaffold, collagen.

*Address for correspondence:

F.H. Lin

Institute of Biomedical Engineering

National Taiwan University

Taipei 100, Taiwan, ROC

Telephone Number: 886-2-23123456 ext.88766

FAX Number: 886-2-23940049;

E-mail: double@ntu.edu.tw

\section{Introduction}

Millions of people worldwide are blind from corneal disease or damage (Thylefors et al., 1995). Although corneal transplantation and Descemet's stripping endothelial keratoplasty (DSEK) have a high success rate (Lee et al., 2009), the shortage of donor corneas remains a problem. Moreover, successful human corneal allografts not only depend upon the availability of donor corneas but also are detrimentally affected by aggressive immune responses. The development of artificial corneas (keratoprostheses) is a promising alternative to obtaining tissue replacements for corneal transplantation. Especially to patients who are blind due to corneal defects, artificial corneas could potentially benefit and the demand is increasing.

In the past decade, breakthroughs have been achieved in corneal tissue reconstruction with fully synthetic chemical polymer technology, taking advantage of the properties of biopolymers with lower mechanical strength. Besides, recent progress in tissue bioengineering is rapidly contributing to the development of many types of tissues, including cornea. In the hope of making corneal substitutes more widely available for visual rehabilitation, investigations are underway in the areas of core-and-skirt keratoprostheses (Kirkham and Dangel, 1991), biosynthetic tissue replacements (Griffith and Osborne, 1999; Li et al., 2003), and thermo-responsive celldetachable substrates for corneal cell sheet engineering (Kruse, 1994; Nishida et al., 2004). Compared with synthetic polymers for artificial corneas, tissue engineering-based implants could reduce the possibility of rejection and complications arising from surgery, including bacterial infection, enzymatic degradation of surrounding tissue, and poor stabilization.

Tissue engineering requires a porous, biodegradable scaffold to replicate the natural extracellular matrix $(\mathrm{ECM})$, which serves to organize cells spatially, provide them with environmental signals and direct site-specific cellular regulation (Wang et al., 2006). Pore size, pore number, and surface area are widely recognized as important parameters for scaffolds used in tissue engineering. Other architectural features such as pore shape and pore wall morphology of the scaffold material have also been suggested as important for cell seeding, migration, growth, and new tissue formation in three dimensions (Chen et al., 2002; Yang et al., 2001). In choosing appropriate material as the scaffold for use in 
corneal tissue engineering, the effects of corneal cell proliferation and migration on the material need to be considered in advance (Orwin and Hubel, 2000). Collagenbased materials are ideal for soft-tissue engineering because of their superior biocompatibility (Soiderer et al., 2004). In this study, we present the design, development, and preliminary evaluation of an acellular, decalcified fabricated scaffold that fits the need for the design of current corneal prostheses. We developed a fish scalederived collagen scaffold which is cytocompatible for use as an in vitro template for culturing the corneal cells. Acellularized and decalcified fish scales appeared to favor cell proliferation and biosynthetic activity after 7 days of cultivation. Our results demonstrate the potential of the fish scales-derived material to be developed as a new scaffold for corneal tissue engineering.

\section{Materials and Methods}

\section{Acellular scaffold preparation}

Tilapias (approximately $200 \mathrm{~g}$ ) were obtained from a commercial dealer in Taipei. After transfer to the laboratory, fresh scales were immediately harvested and soaked in distilled water to clean them. The procedure used to remove the cellular components from the fish scales was based on a method previously reported (Courtman et al., 1994). To increase pore sizes and porosity within the test samples, the acellular tissues were additionally treated with acetic acid (Chang et al., 2004). The resulting acellularized fish scales were rinsed extensively with and stored in sterilized phosphate-buffered saline (PBS, pH 7.4).

\section{Decalcification of the scaffolds}

Decalcification of the material was performed by being immersed in 5\% nitric acid for 6-16 hours at room temperature (RT). The materials were further decalcified by being immersed in $300 \mathrm{ml}$ of Solution A (10\% EDTA, $2 \%$ nitric acid) for $2-3$ days at $4{ }^{\circ} \mathrm{C}$ with renewal of Solution A daily depending on the degree of mineralization of the scales. After decalcification, samples were rinsed with $70 \%$ ethanol and stored in sterilized PBS at $4{ }^{\circ} \mathrm{C}$ for study.

\section{Harvesting corneal cells}

To harvest corneal cells, 10 rabbit corneas were obtained from 5 adult New Zealand white rabbits sacrificed by lethal intracardiac injection of potassium chloride under general anesthesia. Corneas were rinsed with saline containing 300 $\mathrm{U} / \mathrm{ml}$ penicillin and $0.3 \mathrm{mg} / \mathrm{ml}$ streptomycin. Freshly obtained rabbit corneas were preserved at $4^{\circ} \mathrm{C}$ in Dulbecco's modified Eagle's medium (DMEM; SigmaAldrich, St. Louis, MO, USA) supplemented with $100 \mathrm{U} /$ $\mathrm{ml}$ penicillin, $0.1 \mathrm{mg} / \mathrm{ml}$ streptomycin and $0.25 \mu \mathrm{g} / \mathrm{ml}$ amphotericin B (Sigma-Aldrich,) until use. All corneas were processed within 6 hours after extraction. All animals were treated according to the national and international rules of animal welfare, including the ARVO Statement for the Use of Animals in Ophthalmic and Vision Research.

Corneas were mechanically dissected into small pieces and seeded onto the scaffolds, which had been placed one piece per well in 48-well plates. The cells were grown in
DMEM supplemented with $10 \%$ fetal calf serum (FCS; Sigma-Aldrich), $4 \mathrm{mM}$ L-glutamine, $24 \mathrm{mg} / \mathrm{ml}$ adenine and $1 \%$ antibiotic solution (Invitrogen-Gibco, Karlsruhe, Germany). In all cases, cells were incubated at $37^{\circ} \mathrm{C}$ in a humidified atmosphere with $5 \% \mathrm{CO}_{2}$ in air. The culture medium was refreshed every 2 days.

\section{Scanning electron microscopy}

Scanning electron microscopy was used to examine the morphological characteristics of corneal cells cultured onto the acellular decalcified scaffold. The scaffolds were trimmed with a punch ( $4 \mathrm{~mm}$ in diameter) and put onto 24-well culture plates. Corneal debris were plated on the scaffolds and cultured for $1,2,3$, and 7 days at $37^{\circ} \mathrm{C}$ in a $\mathrm{CO}_{2}$ incubator. The medium was changed every 2 days during the culture period. Loosely adherent and unbound cells were removed from the culture wells by aspiration and the wells were washed twice with PBS. The remaining attached cells were fixed in $2.5 \%$ glutaraldehyde in PBS ( $\mathrm{pH} 7.4$ ) for $10 \mathrm{~min}$. The fixative was then aspirated. After being washed in PBS, scaffolds were dehydrated in a graded series of ethanol solutions. After critical point drying (Quorum Technologies, model E3100, Guelph, Ontario, Canada), the samples were sputtered with gold using a SEM coating system (SPI, Sputter Coater11430, West Chester, PA, USA), and the probes were examined by scanning electron microscopy (JEOL, JSM-5610, Tokyo, Japan).

\section{Confocal microscopy}

Cells grown on the scaffolds for the indicated time periods were washed with PBS and fixed in 3.7\% formaldehyde (Sigma-Aldrich) for 15 minutes at room temperature and then permeabilized with 1\% Triton X-100 (Sigma-Aldrich) for 5 minutes. After washing, cells were blocked with $10 \%$ normal goat serum (NGS, Vector Labs, Burlingame, CA, USA) and $5 \%$ bovine serum albumin (BSA, SigmaAldrich) in PBS for 1 hour at room temperature and incubated with Hoechst 33342 in staining buffer (1\% NGS and $1 \% \mathrm{BSA}$ in PBS) for 20 minutes at room temperature to visualize the nucleus. F-actin was visualized using Alexa Fluor 488 phalloidin (1:300; Invitrogen). Image quantification of scaffold area and cell area was accomplished by confocal microscopy.

\section{Cell culture, DAPI staining and direct cell nuclei counting}

SIRC rabbit corneal cells (ATCC number: CCL-60) were cultured at $37^{\circ} \mathrm{C}$ in $5 \% \mathrm{CO}_{2}$ and water-saturated atmosphere in Eagle's minimum essential medium (SigmaAldrich) supplemented with $10 \%$ heat-inactivated fetal bovine serum (Gemini Bio-products, West Sacramento, CA), $1.5 \mathrm{mg} / \mathrm{ml}$ sodium bicarbonate (Sigma-Aldrich), 0.11 $\mathrm{mg} / \mathrm{ml}$ sodium pyruvate (Sigma-Aldrich), $100 \mathrm{U} / \mathrm{ml}$ penicillin, $0.1 \mathrm{mg} / \mathrm{ml}$ streptomycin and $0.25 \mu \mathrm{g} / \mathrm{ml}$ amphotericin B (Sigma-Aldrich). For nuclei staining and counting, cells were plated onto the scaffolds which had been placed one piece per well in 24-well plates at the density of $1 \times 10^{5}$ cells/well and cultured for the indicated time periods. At the end of each cultivation, samples were rinsed in PBS, xed in 4\% paraformaldehyde in PBS, 


\section{(A)}

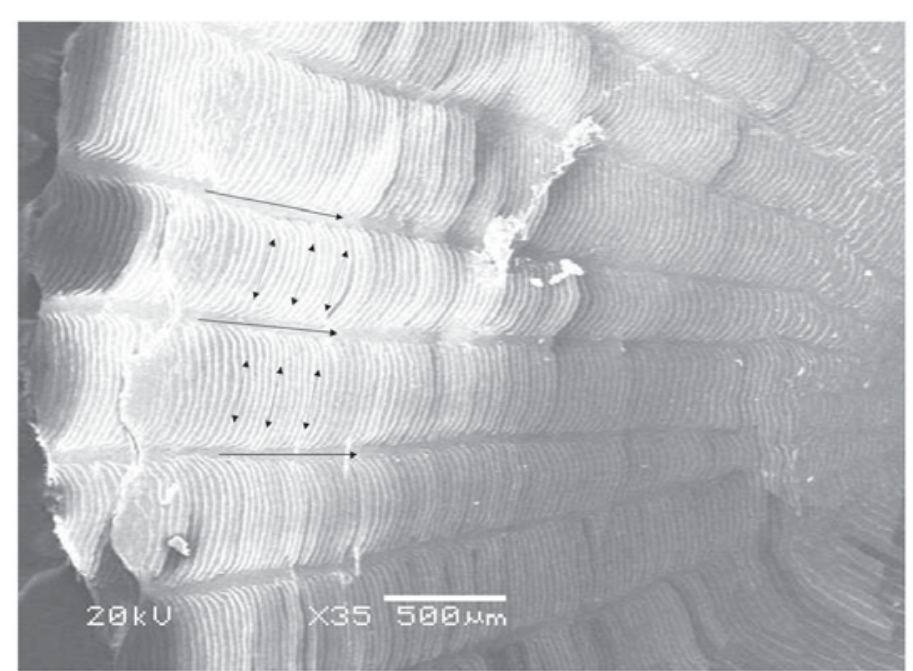

(B)

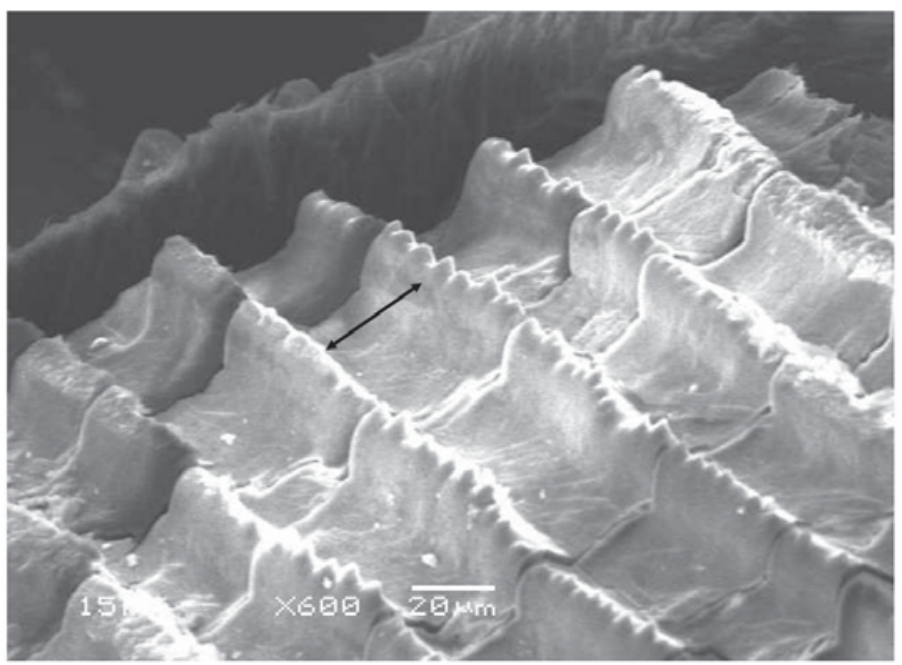

(C)

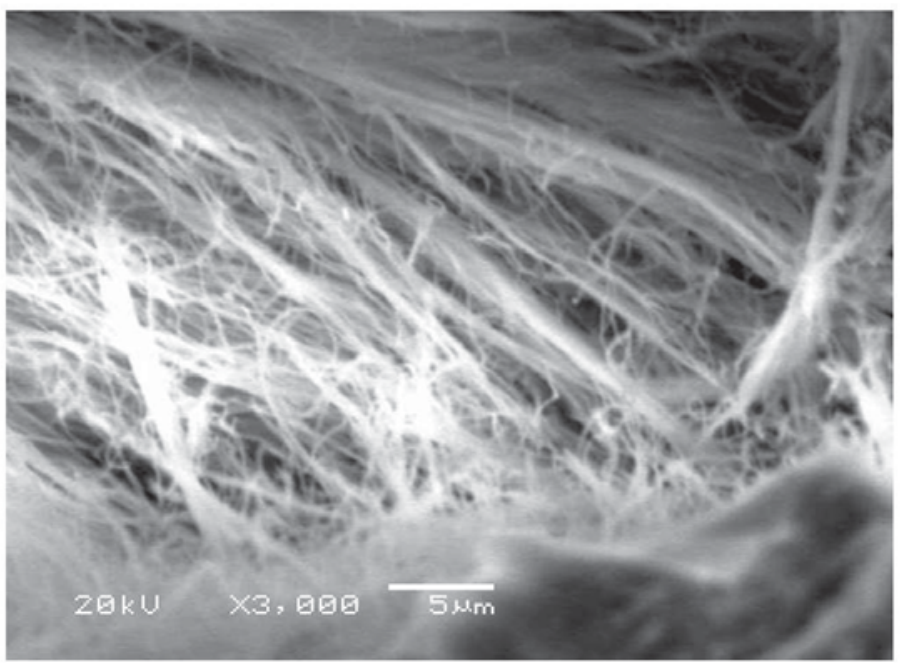

Fig. 1. SEM micrographs of the acellularized fish scale. A: Patterned structure of the material. After the acellularization and decalcification processes, the natural architecture of the material was still maintained, and thereby forming the oriented channels. B: Width of the microchannel. The foundation for guidance of cells involved in the regeneration process is characterized by the remarkable degree of orientation with channel width around $30 \mu \mathrm{m}$. C: Microstructure of the acellularized scaffold. The microstructrue of the scaffold shows us that the intact extracellular matrix is not destroyed after the acellularization process. The arrows and the double-head arrows in (A) indicate the possible guiding directions on the scaffold. Arrows denote the channel width $(30 \mu \mathrm{m})$ in (B). 
(A)

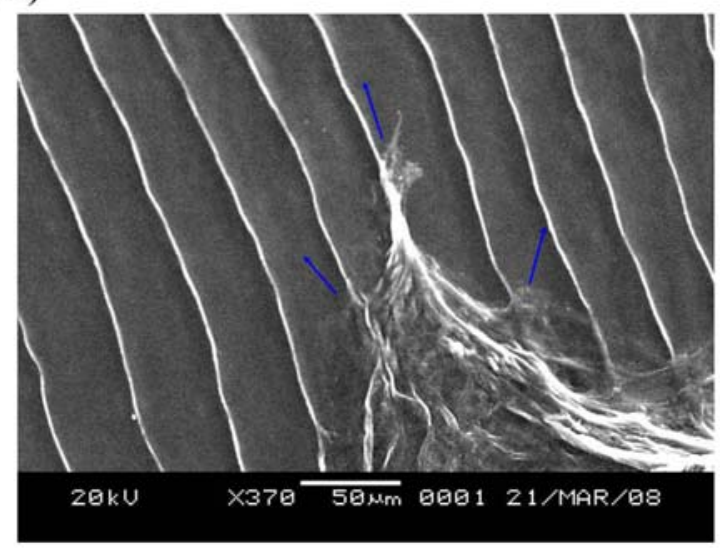

(B)

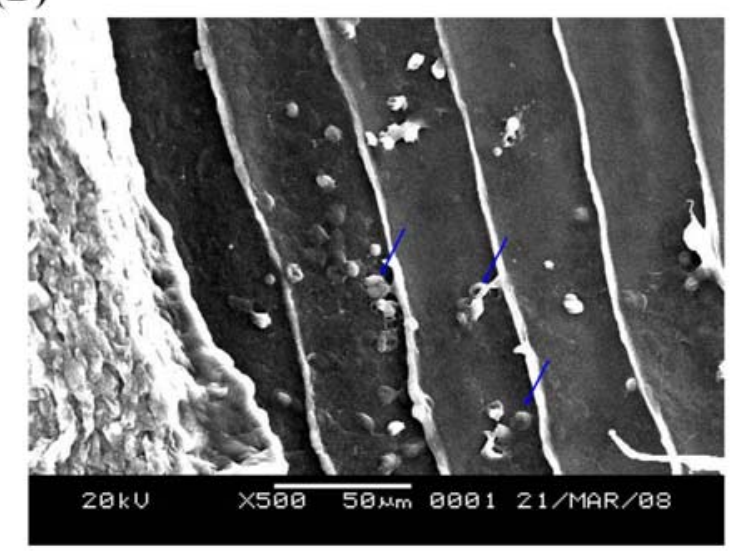

(C)

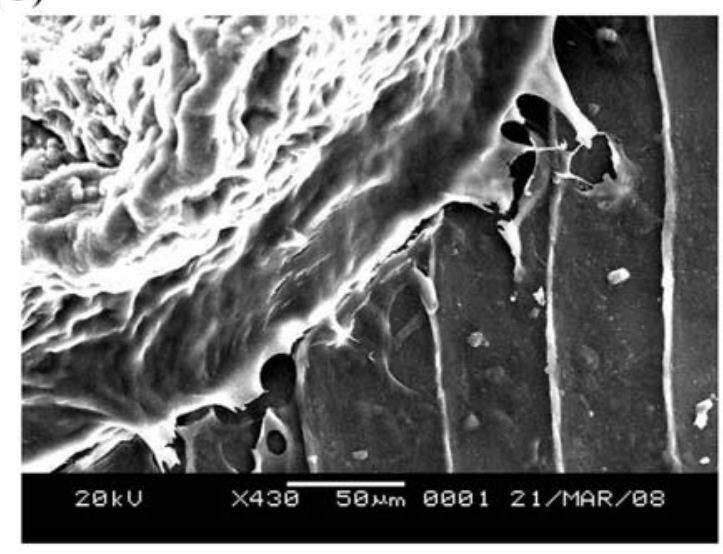

(D)

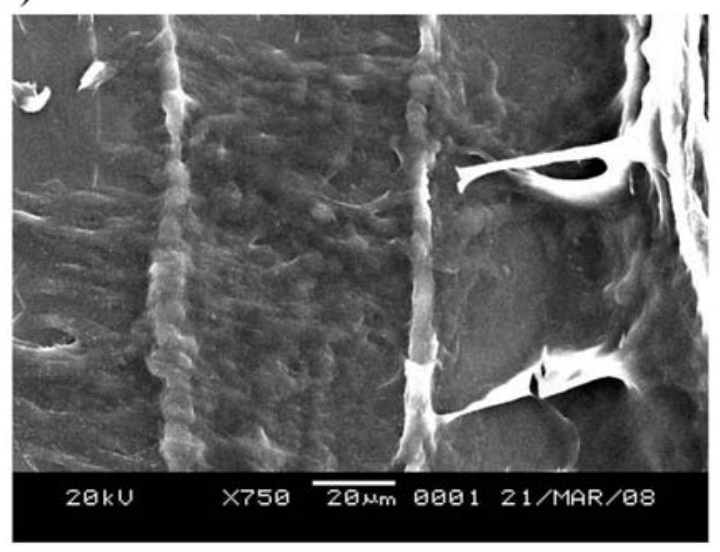

Fig. 2. Micrographs of the corneal cells cultivated on the scaffold after different time periods of cultivation. A: Arrows indicate the directions of corneal cell migration into microchannel after 24 hours of cultivation. B: Dispersed corneal cells reveal the close association between cells and scaffold after 48 hours of cultivation. Arrows indicate the cells. C: Corneal cells grown on the scaffold after 3 days of cultivation. D: Illustration of the exuberantly proliferating corneal cells grown within the longitudinal channels after 7 days of culture

permeabilized with $0.1 \%$ TritonX 100 and incubated with 4', 6 diamidine-2' phenylindole dihydrochloride (DAPI, Sigma-Aldrich) for $20 \mathrm{~min}$ to label nuclei. The DAPI stained cells were observed using a uorescence microscope (BX-71, Olympus, Tokyo, Japan). Images were acquired and count stained nuclei in each image.

\section{Statistical analysis}

Where indicated, the data were expressed as mean \pm standard deviation (SD). The results were compared using two-tailed Student's $t$-test and differences were considered as statistically significant when $p<0.05$.

\section{Results}

\section{Characterization of the newly developed scaffold}

Scanning electron photomicrographs revealed a 3 dimensional (3-D), patterned scaffold with a microchannellike structure (Fig. 1A). The widths of these microchannels had a range around $30 \mu \mathrm{m}$ (Fig. 1B), each individual channel possessing a uniform width along its entire length.

\section{Cytocompatibility analysis on the scaffold}

After seeding on the 3-D scaffolds with corneal cells, SEM demonstrated the orientation and morphology of corneal cells and their processes in parallel with the longitudinal guidance channels (Fig. 2). After seeding on the scaffolds, corneal cells rapidly attached to the scaffold surface (Fig. 2A). The cells extended long processes and migrated into the acellular decalcified scaffold (Fig. 2B). After 7 days of culture, corneal cells were shown to migrate deep into the scaffold and demonstrate a homogeneous and dense growth pattern with an orientation along the channels, indicating that the cells grow and migrate along the guidance channels structure of the scaffolds (Fig. 2D).

In general, cell attachment, spreading and proliferation on the scaffold reflect the ability of the scaffold to make contact with the cells. Fewer proliferating cells on a substrate is a sign of weak cell-material interaction, which 
(A)

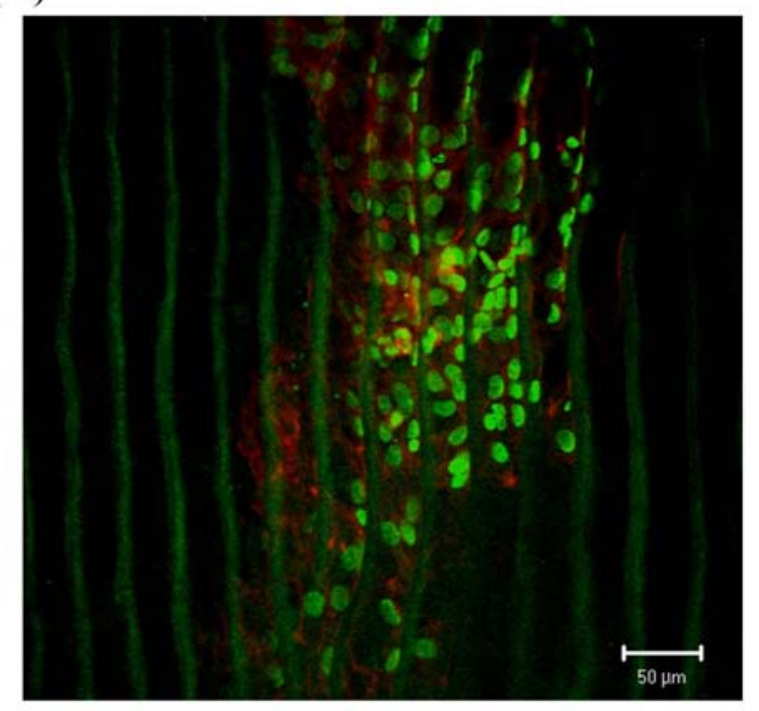

(C)

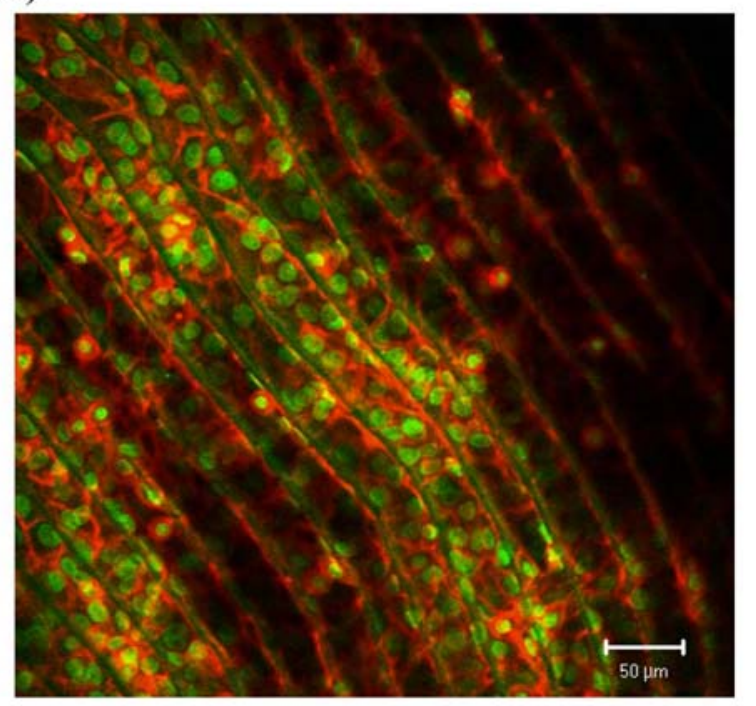

(B)

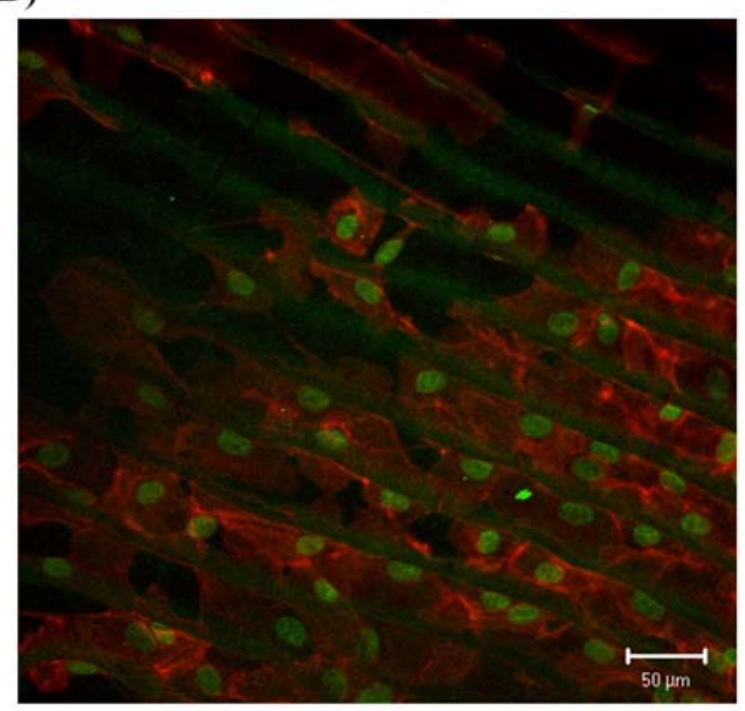

(D)

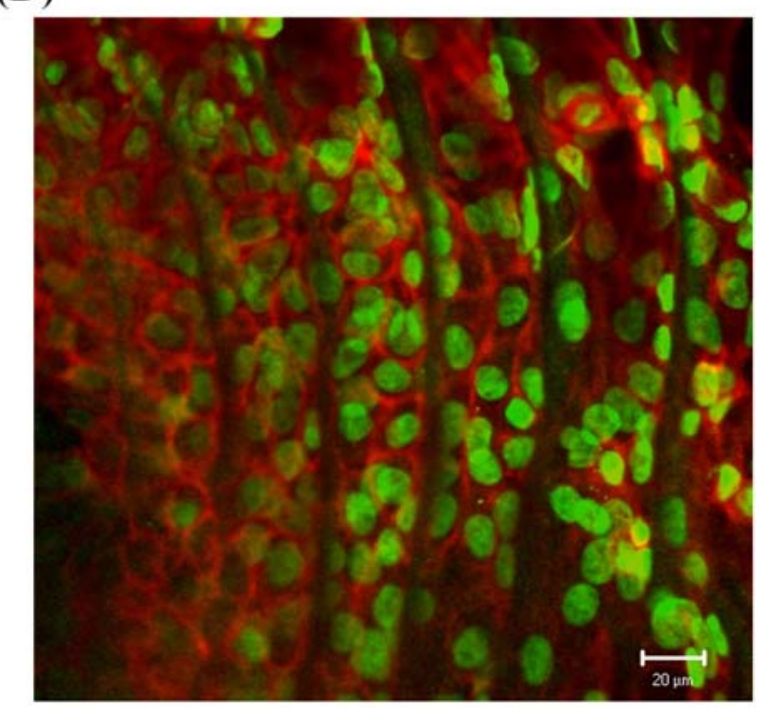

Fig. 3. The distribution of corneal cells cultivated on the acellular scaffold. A-C: The growing corneal cells were visualized after 1 day (A), 2 days (B) and 3 days (C) of cultivation. D: Closer view of cells after 7 days of cultivation. The cells were fixed and stained using Hoechst 33342 (to detect nuclei) and Alexa Fluor 488-phalloidin (for visualization of F-actin). Green, nucei; red, F-actin.

could be followed by cell death (Wang et al., 2006). To test the cytocompatibility of the scaffold with the corneal cells, cell attachment, spreading and morphology were observed under confocal microscopy. The cell morphology was visualized by confocal microscopy after 1 day, 2 days, 3 days and 7 days of culture. The micrograph (Fig. 3A) shows that cells on the scaffold surface after 1 day of culture were mostly round and fewer cells were attached onto the surface in comparison with the longer time periods of cultures. After 2 days of culture, the corneal cells distributed more densely, and contacted each other to form larger aggregates on the scaffold (Fig. 3B). Corneal cells proliferated exuberantly and started stacking in the guidance channels on the scaffold surfaces after more than
3 days of culture (Figs. 3C and 3D).

To assess the corneal cell growth on the scaffolds, SIRC rabbit corneal cells were employed due to the fact that the cultured cells originated from the cell lines are easy to be dispersed and counted. SIRC cells were seeded onto the scaffolds and cultured for various time periods. As determined by direct cell nuclei counting, rabbit corneal cell proliferation on the scaffold was observed and showed a statistically significant increase in cell population during the 7-day culture period ( $p<0.01$; Fig. 4 ). Taken together, the results demonstrate that the fish scale-derived scaffold is cytocompatible with corneal cells and might be applied to production of tissue-engineering based artificial cornea. 


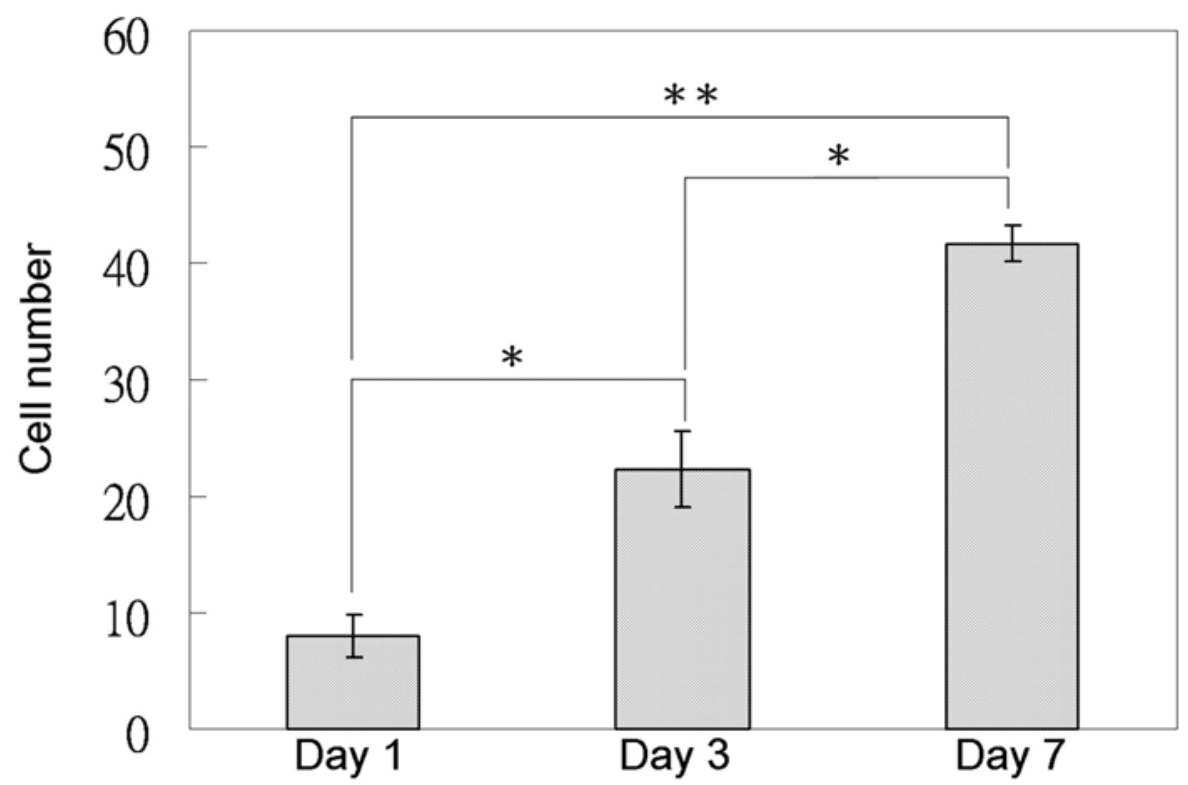

Fig. 4. Quantification of corneal cell growth on the scaffold. SIRC cells were cultured on the scaffolds for various time periods. The cell number was quantified as described in Materials and Methods. Each bar represents the mean $\pm \mathrm{SD}$ calculated from three independent experiments. ${ }^{*} p<0.05 ; * *<0.01$ (two-tailed $t$ test).

\section{Discussion}

The fabrication of artificial corneal substitutes with the long-term transparency, optimal biomechanical properties and regenerative capacity remains a stubborn challenge. In this study, we have developed an acellular, decalcified, fish scale-derived biodegradable scaffold for artificial cornea development. The fabricated material keeps the naturally $3-\mathrm{D}$ microstructure even after being acellularized and decalcified. The 3-D microstructure which is helpful for cell growth and migration is also maintained. Moreover, the material is hydrophilic and permeable to oxygen (see Supplementary Material at the end of the paper). These properties make the scaffold to be a promising material for artificial cornea development.

Using collagen as a biomaterial for providing scaffold used in tissue engineering introduces some disadvantages compared to other materials. These include its low biomechanical stiffness and rapid biodegradation. Further, the high rate of enzymatic degradation of natural collagen in vivo makes stabilization of collagen-based biomaterials necessary (Lee et al., 2001; Ma et al., 2004). Moreover, for tissue engineering, previous studies have demonstrated that high mechanical strength is important for biodegradable polymer scaffolds (Hoerstrup et al., 2000; Shinoka et al., 1995; Shinoka et al., 1998; Stock et al., 2000) or allogenic acellular matrix scaffolds (Steinhoff et al., 2000). Major disadvantages of biodegradable polymer scaffolds include the requirement of reconstruction of the natural three-dimensional structures, and the absence of important ECM proteins in the synthetic polymers (Cheresh et al., 1989; Joshi et al., 1993). Thus, acellularized xenogenic tissues which maintain natural 3-dimensional structures are a promising alternative to biodegradable polymer scaffolds. Acellularized biological matrices have been successfully used for tissue engineering of blood vessels, heart valves, and urinary bladder (Atala, 2000; Nerem and Seliktar, 2001; Steinhoff et al., 2000).

In this study, we focused on the fabrication of a naturally derived, 3-dimentional, micropatterned scaffold, and the acellularizing and decalcification methods were used to generate a mechanically strong scaffold. The basic concept of this study is the use of preformed scaffold material with in vitro seeding of tissue components. In the mean time, during typical processing of fish scale tissue, cells are ruptured, but the cellular debris is largely retained. Various cell extraction methods (e.g., detergent treatment, enzymatic digestion, sonication) have been pursued as means to create completely acellular tissues for use as biomaterial implants, since residual cellular components and lipids within processed tissue may promote undesired effects, such as calcification (Courtman et al., 1994; Ngangan and McDevitt, 2009; Valente et al., 1985) and immune response (Niederkorn, 2007). We treated the acellular materials further by a decalcifying process to reduce the possibility of calcification which was most probably occurred during initial cell migration at the time of in vivo use.

Cultures of epithelial cells or co-culture of epithelial cells and keratocytes on collagen scaffold have been employed for culturing corneal tissue (Geggel et al., 1985; Trinkaus-Randall et al., 1988). We report here a reconstruction of corneal material in vitro for the development of scaffolds for artificial cornea. The use of micropatterned structures provides innovative strategies to guide cell populations to migrate in multiple parallel channels with spatial and functional reconstructions. The cytocompatibility and microstructure properties of the scaffolds are thought to affect the proliferation of the corneal cells. The morphology of corneal cells cultured 
on the scaffolds shown by SEM and confocal microscope demonstrated that the cells spread extensively over the surface of the scaffold (Figs. 2 and 3). Moreover, the corneal cells proliferated proportionally with the culture period (Figs. 3 and 4). Due to the properties of patterned and highly organized structure in our scaffold, corneal cell growth and migration were predominantly guided by the channels (Fig. 1A). The major characteristics of the scaffold, cytocompatibility and microstructure, are not only facilitating cell attachment but also guiding cell migration. After 7 days of culture, corneal cells were observed to grow within the scaffold and fill the channels on the patterned scaffolds (Figs. 2D and 3D). Taken together, our results demonstrate that the acellular, decalcified, biodegradable scaffolds are totally cytocompatible with the corneal cells. The results also suggest that the preserved micro-structure of the scaffold is advantageous to cell migration and spreading on the whole scaffold.

Our newly designed scaffold for application in corneal tissue engineering is attractive for the following reasons. First, acellular animal tissues are employed, which differ from hydrogels in being biodegradable. Second, the derived acellular material is hydrophilic (see Supplementary Material), highly cytocompatible with the host cells (Figs. 2, 3) and with highly patterned structures (Fig. 1), that can readily promote cell conductive properties and bulk tissue integration for regenerating injured corneal tissues. Third, the derived acellular material is wellpermeable to gas (see Supplementary Material), which is a prerequisite for materials using as cornea substitute (Shusterov et al., 2001). In summary, the present study has demonstrated the feasibility of the fish scale-derived scaffold as a superior material for artificial cornea regeneration.

\section{Conclusion}

In conclusion, the focus of artificial cornea research and development has shifted to concepts of tissue engineering with high cytocompatibility, guiding channel-like structure and biodegradable scaffolds. Our study showed that corneal cells proliferated and guiding migrated, and the behavior of the cells was positively influenced by our newly developed biodegradable scaffold. The next phase of the investigation will involve evaluating the ability of the collagen scaffold to be implanted and integrated in vivo. The properties of this acellularized, decalcified fish scales make it a promising biomaterial to act as tissue engineering's scaffold in artificial corneal regeneration.

\section{Acknowledgements}

This study was financially supported by Aeon Astron Corporation Research Center in Taiwan.

\section{References}

Atala A (2000) Tissue engineering for bladder substitution. World J Urol 18: 364-370.

Chang Y, Lee M-H, Liang H-C, Hsu C-K, Sung H-W (2004) Acellular bovine pericardia with distinct porous structures fixed with genipin as an extracellular matrix. Tissue Eng 10: 881-892.

Chen G, Ushida T, Tateishi T (2002) Scaffold design for tissue engineering. Macromol Biosci 2: 67-77.

Cheresh DA, Berliner SA, Vicente V, Ruggeri ZM (1989) Recognition of distinct adhesive sites on fibrinogen by related integrins on platelets and endothelial cells. Cell 58: $945-953$.

Courtman DW, Pereira CA, Kashef V, McComb D, Lee JM, Wilson GJ (1994) Development of a pericardial acellular matrix biomaterial: biochemical and mechanical effects of cell extraction. J Biomed Mater Res 28: 655666.

Geggel H, Friend J, Thoft R (1985) Collagen gel for ocular surface. Invest Ophthalmol Vis Sci 26: 901-905.

Griffith M, Osborne R (1999) Functional human corneal equivalents constructed from cell lines. Science 286: $2169-2172$.

Hoerstrup SP, Sodian R, Daebritz S, Wang J, Bacha EA, Martin DP, Moran AM, Guleserian KJ, Sperling JS, Kaushal S, Vacanti JP, Schoen FJ, Mayer JE, Jr (2000) Functional living trileaflet heart valves grown in vitro. Circulation 102: III-44-49.

Joshi P, Chung C, Aukhil I, Erickson H (1993) Endothelial cells adhere to the RGD domain and the fibrinogen-like terminal knob of tenascin. J Cell Sci 106: 389-400.

Kirkham SM, Dangel ME (1991) The keratoprosthesis: improved biocompatibility through design and surface modification. Ophthalmic Surg 22: 455-461.

Kruse FE (1994) Stem cells and corneal epithelial regeneration. Eye 8: 170-183.

Lee CH, Singla A, Lee Y (2001) Biomedical applications of collagen. Int J Pharm 221: 1-22.

Lee WB, Jacobs DS, Musch DC, Kaufman SC, Reinhart WJ, Shtein RM (2009) Descemet's stripping endothelial keratoplasty: safety and outcomes - a report by the American Academy of Ophthalmology. Ophthalmology 116: 1818-1830.

Li F, Carlsson D, Lohmann C, Suuronen E, Vascotto S, Kobuch K, Sheardown H, Munger R, Nakamura M, Griffith M (2003) Cellular and nerve regeneration within a biosynthetic extracellular matrix for corneal transplantation. Proc Natl Acad Sci U S A 100: 1534615351.

Ma L, Gao C, Mao Z, Zhou J, Shen J (2004) Enhanced biological stability of collagen porous scaffolds by using amino acids as novel cross-linking bridges. Biomaterials 25: 2997-3004.

Nerem RM, Seliktar D (2001) Vascular tissue engineering. Annu Rev Biomed Eng 3: 225-243.

Ngangan AV, McDevitt TC (2009) Acellularization of embryoid bodies via physical disruption methods. Biomaterials 30: 1143-1149. 
Niederkorn JY (2007) Immune mechanisms of corneal allograft rejection. Curr Eye Res 32: 1005-1016.

Nishida K, Yamato M, Hayashida Y, Watanabe K, Maeda N, Watanabe H, Yamamoto K, Nagai S, Kikuchi A, Tano Y, Okano T (2004) Functional bioengineered corneal epithelial sheet grafts from corneal stem cells expanded ex vivo on a temperature-responsive cell culture surface. Transplantation 77: 379-385.

Orwin EJ, Hubel A (2000) In vitro culture characteristics of corneal epithelial, endothelial, and keratocyte cells in a native collagen matrix. Tissue Eng 6: 307-319.

Shinoka T, Breuer CK, Tanel RE, Zund G, Miura T, Ma PX, Langer R, Vacanti JP, Mayer JJE (1995) Tissue engineering heart valves: valve leaflet replacement study in a lamb model. Ann Thorac Surg 60: 513-516.

Shinoka T, Shum-Tim D, Ma PX, Tanel RE, Isogai N, Langer R, Vacanti JP, Mayer JE, Jr. (1998) Creation of viable pulmonary artery autografts through tissue engineering. J Thorac Cardiovasc Surg 115: 536-546.

Shusterov YA, Bragin VE, Bykanov AN, Eliseeva EV (2001) Refractive tunnel keratoplasty with synthetic implants modified by a gas-discharge plasma. Artif Organs 25: 983-993.

Soiderer EE, Lantz GC, Kazacos EA, Hodde JP, Wiegand RE (2004) Morphologic study of three collagen materials for body wall repair. J Surg Res 118: 161-175.

Steinhoff G, Stock U, Karim N, Mertsching H, Timke A, Meliss RR, Pethig K, Haverich A, Bader A (2000) Tissue engineering of pulmonary heart valves on allogenic acellular matrix conduits: in vivo restoration of valve tissue. Circulation 102: III-50-55.

Stock UA, Nagashima M, Khalil PN, Nollert GD, Herden T, Sperling JS, Moran A, Lien J, Martin DP, Schoen FJ, Vacanti JP, Mayer JE, Jr (2000) Tissue-engineered valved conduits in the pulmonary circulation. $\mathrm{J}$ Thorac Cardiovasc Surg 119: 732-740.

Thylefors B, Negrel AD, Pararajasegaram R, Dadzie KY (1995) Global data on blindness. Bull World Health Organ 73: 115-121.

Trinkaus-Randall V, Newton A, Franzblau C (1988) Influence of substratum on corneal epithelial cell growth and protein synthesis. Invest Ophthalmol Vis Sci 29: 18001809.

Valente M, Bortolotti U, Thiene G (1985) Ultrastructural substrates of dystrophic calcification in porcine bioprosthetic valve failure. Am J Pathol 119: 1221.

Wang J-H, Hung C-H, Young T-H (2006) Proliferation and differentiation of neural stem cells on lysine-alanine sequential polymer substrates. Biomaterials 27: 3441-3450.

Yang S, Leong K-F, Du Z, Chua C-K (2001) The design of scaffolds for use in tissue engineering. part I. traditional factors. Tissue Eng 7: 679-689.

\section{Supplementary Material}

\section{Supplementary Materials and Methods}

\section{Hydrophilicity test}

The hydrophilicity of the scaffold was determined by measuring the water contact angle. A water drop was deposited on the surface of the scaffold using a pipette, and the contact angle between the drop of water and the scaffold was estimated according to the manufacturer's instruction (Digidrop Goniometer, GBX, France).

\section{Oxygen permeability test}

The oxygen permeability (Dk) of the scaffold swollen in PBS was determined using Oxygen Permeometer Model $201 \mathrm{~T}$ (Createch Inc., Albany, CA, USA) fitted with a polarographic cell in an enclosed box at near $100 \%$ relative humidity, $35^{\circ} \mathrm{C}$.

\section{Supplementary Results}

Hydrophilicity and oxygen permeability of the scaffold The hydrophilicity and oxygen permeability of the scaffold were determined. The hydrophilicity of the scaffold was determined and interpreted in terms of water contact angle. Surfaces with a water contact angle less than $90^{\circ}$ are called hydrophilic (Shirtcliffe et al., 2006). The mean water contact angle $(\theta)$ of the scaffold was measured as $6^{\circ}$ and thus read as extremely hydrophilic. The oxygen permeability (Dk) of the scaffold swollen in PBS was determined using Oxygen Permeometer. The oxygen permeability was determined as $48.15 \times 10^{-11}\left(\mathrm{~cm}^{2} \times \mathrm{ml}\right.$ $\left.\mathrm{O}^{2}\right) /(\mathrm{sec} \times \mathrm{ml} \times \mathrm{mmHg})$. These results indicated that the scaffold material was hydrophilic and with superior oxygen permeability. Hence the newly developed material is considered appropriate for ophthalmologic application.

\section{Supplementary Reference}

Shirtcliffe NJ, McHale G, Newton MI, Pyatt FB, Doerr SH (2006) Critical conditions for the wetting of soils. Appl Phys Lett 89: 094101-094103. 